\title{
Mechanical Properties of Polyolefin Fiber-Reinforced Light Weight Concrete
}

\author{
Arash Sedaghatdoost ${ }^{a^{*}}$, Morteza Amini ${ }^{b}$ \\ ${ }^{a}$ Civil Engineering Department, Najafabda University, Isfahan, Iran. \\ ${ }^{b}$ Civil Engineering Department, Isfahan University, Isfahan, Iran. \\ Received 07 August 2017; Accepted 24 September 2017
}

\begin{abstract}
The utilization of polyolefin fibers in reinforced concrete can potentially enhance the properties of the concrete by changing the interfacial properties of the fiber-matrix interface. The objective of this research was to determine the mechanical properties of polyolefin fiber reinforced lightweight concrete (LWC). Compressive, flexural, and splitting tensile strengths of the sample were measured. Polyolefin fibers were added to the reinforced composite in variable amounts $(0-2 \%)$. The lightweight concrete was designed to achieve compressive strength target of at least $30 \mathrm{MPa}$ with a density value of 1800 $\mathrm{kg} / \mathrm{m}^{3}$ after 28 days of storage. The results showed that the highest compressive strength was obtained in LWC containing $1 \%$ fiber led to an increase of about $8 \%$. However, a reduction in compressive strength was observed when the amount of fiber was increased. Moreover, increasing the amount of fiber presented a growth in rupture modulus as well as splitting tensile strength.
\end{abstract}

Keywords: Fiber Reinforced Concrete; Polyolefin Fiber; Light Weight Concrete; Mechanical Properties.

\section{Introduction}

The employment of lightweight concrete in a building has many advantages such as saving time, cost effective, handling, and higher thermal insulation [1]. The replacement of natural aggregate with natural or artificial lightweight aggregate unit reduces weight of concrete [2].

The addition of admixture with high quality to concrete could make them inexpensive as well as improvement of strength and durability [3]. Added fibers to concrete reduce the effect of concrete shrinkage and creep [4]. There are always micro or medium cracks in cement based composites, which cause a decrease in durability due to the presence of water, chloride-ion, and carbon dioxide penetrated into the concrete and thereby induce a steel corrosion [5]. Fibers within the cement based materials prevent or control the cracks and improve the tensile strength, ductility, toughness, and durability of the concrete [6,7]. There are variable fibers including carbon, polyvinyl alcohol, steel, and glass fibers that may theoretically increase the strength as a result of high modulus whereas some low strength fibers such as polypropylene, nylon, and acrylic improve ductility and reduce cracking [8].

Steel fibers have been commonly used to raise the mechanical properties of concrete, on the other hand they suffer from disadvantages. The durability of concrete may be affected by corrosion of steel while high density of steel causes the extra costs to transport and handling as well as an increase in the weight of a structure [4, 9]. Polymer fibers may

* Corresponding author: arashsedaghatdoost1@gmail.com

DOI: http://dx.doi.org/10.21859/cej-030912

> This is an open access article under the CC-BY license (https://creativecommons.org/licenses/by/4.0/).

(C) Authors retain all copyrights. 
offer a solution to overcome the abovementioned challenges. Polymer fibers compared with steel fiber provide the advantages of light weight, efficient distribution and high corrosion resistance [10].

Polyolefin fibers with low aspect ratio and available in various lengths and diameters, may improve the structural properties of concrete similar to the steel fibers. They can be mixed in large quantities, as much as $8 \%$ (by volume) without causing any balling, segregation or increase in air entrainment within concrete [11]. The polyolefin fibers are more flexible and ductile with having greater influence on strength than steel fibers. It has been previously reported that polyolefin fibers improve the toughness and strain capacity $[12,13]$.

It has been shown that addition of $0.8 \%$ polyolefin fiber in concrete, enhanced the compressive, splitting strengths, and rupture modulus by $3.3,10$, and $17.5 \%$, respectively [10]. Another study presented that in the presence of polyolefin the flexural strength can be increased by $13 \%$ and the growth or propagation of cracks were decreased up to $70 \%$ [5]. Investigation on a bond mechanism between the polyolefin fiber and cement paste showed that the bond was improved with an increase of the fiber superficial roughness [12].

In this study we focused on the polyolefin fiber reinforced system. We evaluated the engineered properties of lightweight concrete, which comprise Polyolefin fibers and Light Expanded Clay Aggregate in the mixtures. The results of mechanical properties for concrete composites are then compared.

\section{Materials and Mix Proportioning}

\subsection{Materials}

The cement used in this study was ordinary Portland cement type 2 (Ardestan cement, Iran) with Iranian standard (ISIRI), which was jointly prepared and kept in our laboratory at Khorasgan University. The physical and chemical characteristics of the cement are given in Table 1 and 2, respectively.

Table1. Physical properties of cement

\begin{tabular}{cc}
\hline Physical properties & Result \\
\hline Specific gravity $\left(\mathrm{cm}^{2} / \mathrm{g}\right)$ & 3285 \\
Autoclave expansion & 0.26 \\
Initial time setting (minute) & $95 \pm 5$ \\
Final time setting (minute) & $150 \pm 10$ \\
Blaine surface $\mathrm{kg} / \mathrm{m}^{3}$ & $3000 \pm 50$ \\
Compressive strength $(7$ days $) \mathrm{Kg} / \mathrm{cm}^{2}$ & 225 \\
Compressive strength $(28$ days $) \mathrm{Kg} / \mathrm{cm}^{2}$ & 412 \\
\hline
\end{tabular}

Table 2. Chemical properties of cement

\begin{tabular}{ccccccccccc}
\hline Chemical properties & $\mathrm{SiO}_{2}$ & $\mathrm{CaO}$ & $\mathrm{Al}_{2} \mathrm{O}_{3}$ & $\mathrm{Na}_{2} \mathrm{O}$ & $\mathrm{Fe}_{2} \mathrm{O}_{3}$ & $\mathrm{SO}_{3}$ & $\mathrm{C}_{3} \mathrm{~A}$ & $\mathrm{CL}$ & $\mathrm{K}_{2} \mathrm{O}$ & $\mathrm{MgO}$ \\
\hline Percent & 22 & 64 & 5 & 0.25 & 3.82 & 1.5 & 6.5 & 0.019 & 0.49 & 1.9 \\
\hline
\end{tabular}

Light Expanded Clay Aggregate (LECA) was produced by Iran LECA Co. with 95\% size range of $\leq 10 \mathrm{~mm}$. LECA density was determined according to ASTM C29 Standard. The results of LECA granular and bulk density in compacted and non- compacted modes are shown in Table 3.

Table 3. Density of Light Expanded Clay Aggregate

\begin{tabular}{ccc}
\hline $\begin{array}{c}\text { Un compacted Bulk Density } \\
\left(\mathbf{K g} / \mathbf{m}^{\mathbf{3}}\right)\end{array}$ & $\begin{array}{c}\text { Compacted bulk Density } \\
\left(\mathbf{K g} / \mathbf{m}^{\mathbf{3}}\right)\end{array}$ & $\begin{array}{c}\text { Granular Density } \\
\left(\mathbf{K g} / \mathbf{m}^{\mathbf{3}}\right)\end{array}$ \\
\hline 519.52 & 549.1 & 967 \\
\hline
\end{tabular}

LECA granular density experiment was carried out according to Archimedes law and the method recommended by standards that are prepared according to LECA company. Briefly, a graduated cylinder was filled with $150 \mathrm{~g}$ of LECA followed by addition of $400 \mathrm{ml}$ water.

In order to determine the mix designs and due to the fact that LECA water absorption is time dependent and its moisture content can be varied by changing in the environmental conditions, therefore measuring the absorption of lightweight grain is very important. Thus, water absorption was measured periodically in 30, 60min and $24 \mathrm{hrs}$ based on 
the ASTM C127 standard method and the average is reported. The obtained water absorption amount was $6 \%$. In Figure 1. shows the appearance of LECA.

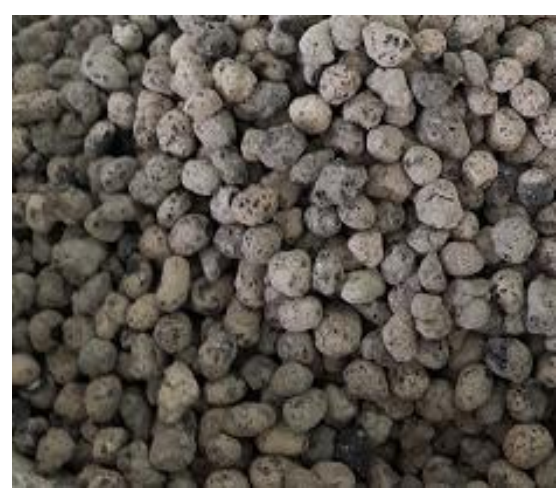

Figure 1. LECA

The washed river $(0-5 \mathrm{~mm})$ obtained from Isfahan Sofe mine was utilized. While the water absorption of the sand was $2.9 \%$, its fineness module was equal to 3.38 .

Super plasticizer based on the poly-carboxylic ether with $49 \%$ of pure materials and natural density of $1110 \mathrm{~kg} / \mathrm{m}^{3}$ was purchased from AFROUZ chemical company. The percentage of plasticizer cloud was set according to concrete workability in mix design .

The optimum fiber length and percentage were selected based on the trial experiments. Table 4. compares the main characteristics of the fiber, material properties and geometrical patterns while Figure 2. shows the appearance.

Table 4. Properties of polyolefin fiber

\begin{tabular}{cc}
\hline Property & Results \\
\hline Shape & Straight \\
Young modulus & $2647 \mathrm{MPa}$ \\
Tensile strength & $275 \mathrm{MPa}$ \\
Elongation at break & $15 \%$ \\
Density & $900 \mathrm{Kg} / \mathrm{m}^{3}$ \\
Length & $50 \mathrm{~mm}$ \\
\hline
\end{tabular}

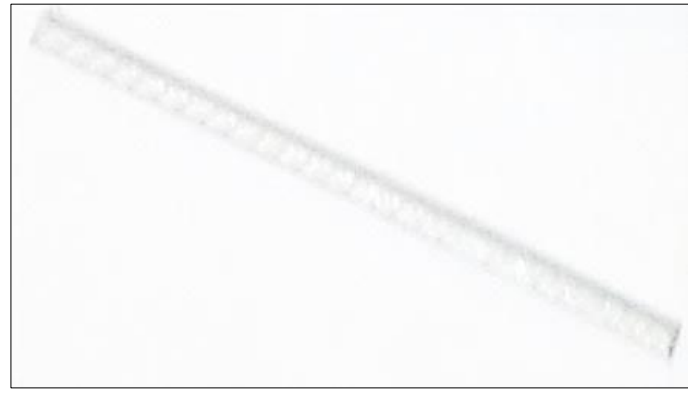

Figure. 2. Polyolefin fiber

\subsection{Mix Proportioning}

The lightweight concrete was prepared by weighing the mixture compositions according to the mix design. After determination of the physical properties and aggregate gradation, several concrete proposals were experimentally made and final design was determined based on strength and workability considerations. Compressive strength target of at least $30 \mathrm{MPa}$ and a density of $1800 \mathrm{Kg} / \mathrm{m} 3$ were considered for selecting mix design and accordingly experimental plans were assessed and finally, proposed plan was selected for this project. Table 5. shows the mix design.

In order to reduce the negative effects of water absorption by lightweight aggregates in preparation of the concrete mixture and avoiding fast workability reduction of new lightweight concrete performance, a certain amount of water equivalent to the difference between half an hour water absorption and moisture content of lightweight grain was added to LECA before mixing materials. The water was considered effective in calculation of the water to cement ratio. water was added to LEAC and mixed properly for $10 \mathrm{~min}$. Proportioning materials, mixing, molding, compression and processing of the concrete were performed the same as ordinary concrete. 
Initially, the cement, sand and lightweight aggregate were mixed using a mixer in dry form, then water was added followed by addition of the super plasticizer to the mixture. Fibers were added gently to mixer by the operator to distribute them properly within the mixture. Mix designs are presented in Table 5. and in Figure 3. shows the fiber added in mixture.

Table 5. Concrete mix proportions

\begin{tabular}{ccccccc}
\hline Sample & Fiber $(\%)$ & Super plasticizer $(\%$ of cement weight) & W/C & Sand $\left(\mathbf{k g} / \mathbf{m}^{\mathbf{3}}\right)$ & LECA $\left(\mathbf{k g} / \mathbf{m}^{3}\right)$ & Cement $\left(\mathbf{k g} / \mathbf{m}^{3}\right)$ \\
\hline $\mathrm{N}_{1}$ & 0 & 0.35 & 0.35 & 820 & 270 & 450 \\
$\mathrm{~N}_{2}$ & 0.5 & 0.35 & 0.35 & 820 & 270 & 450 \\
$\mathrm{~N}_{3}$ & 1 & 0.35 & 0.35 & 820 & 270 & 450 \\
$\mathrm{~N}_{4}$ & 1.5 & 0.35 & 0.35 & 820 & 270 & 450 \\
$\mathrm{~N}_{5}$ & 2 & 0.35 & 0.35 & 820 & 270 & 450 \\
\hline
\end{tabular}

As can be seen in Table 5, for comparison of fiber reinforced concrete with the normal concrete, a control sample named N1 was constructed in accordance with the mix design given in Table 5. It is noteworthy to note that the results of different experiments were in accordance with the number of required samples. Also, average amounts of measured values were used to verify the results.

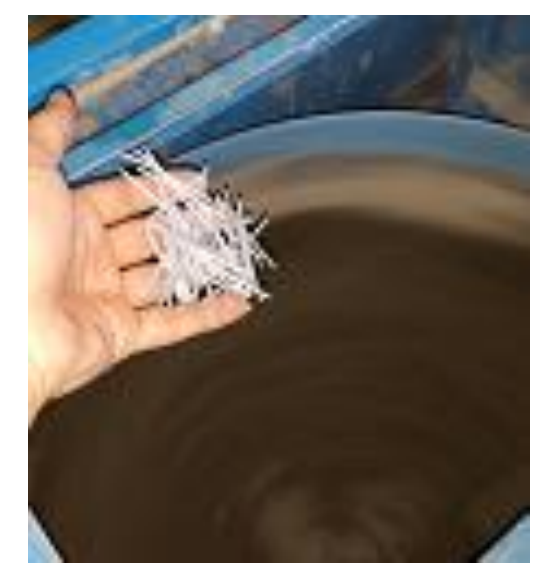

Figure 3. Added Polyolefin fiber in mixture

\subsection{Experimental Program and Test Methods}

Compressive strength test of hardened concrete was performed on cubic specimen with dimensions of $150 \times 150 \times 150$ $\mathrm{mm}$ based on the BS 1881 (Part 116) standard method. Casting molded shows in Figure 4. For each mix design, 6 compressive specimens were made and they were tested after 7 and 28 days of storage. Sample processing was done in water pool. The employed machine for determination of the compressive strength had a capacity of 200 tons.

To determine the flexural strength of hardened concrete, specimens with dimensions of $100 \times 100 \times 500 \mathrm{~mm}$ were used and the experiment was performed according to ASTM C78 Standard method. The test was done on processed specimen after 28 days of storage in a water pool. The tensile strength was measured (ASTM C469 standard method) on cylindrical specimens with dimensions of $300 \times 150 \mathrm{~mm}$ after 28 days of storage.

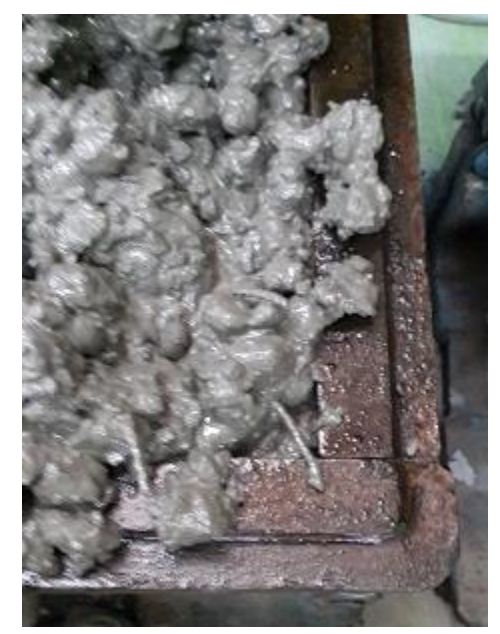

Figure 4. Casting concrete in mould 


\section{Results and Discussion}

\subsection{Compressive Strength}

The compressive strength of samples aged 7 and 28 days was tested for three samples per design and the average results are presented in Table 6. The 7 and 28-days compressive strength test results of lightweight concrete are shown in Figure 5. As it was shown in the figure, the increase of compressive strength of concrete.

The compressive strength of N2, N3 and N4 samples in comparison with plain concrete has been increased 1.16, 8.03 and 3.73 percent respectively.

It seems that, we can find the reason of increase in compressive strength, particularly in relation to the N3 sample compared with control sample, in higher density of mix design and concrete components adhesion. It seems that adding Polyolefin fibers to lightweight concrete has led to better location of concrete aggregates and ingredients, and a compact structure has been created against compressive loads.

Table 6. Test results for compressive strength

\begin{tabular}{ccc}
\hline Sample & Average compressive strength for 7 days (MPa) & Average compressive strength for 28 days (MPa) \\
\hline $\mathrm{N}_{1}$ & 33.2 & 36.97 \\
$\mathrm{~N}_{2}$ & 33.4 & 37.4 \\
$\mathrm{~N}_{3}$ & 35.3 & 39.94 \\
$\mathrm{~N}_{4}$ & 33.95 & 38.35 \\
$\mathrm{~N}_{5}$ & 32.25 & 35.96 \\
\hline
\end{tabular}

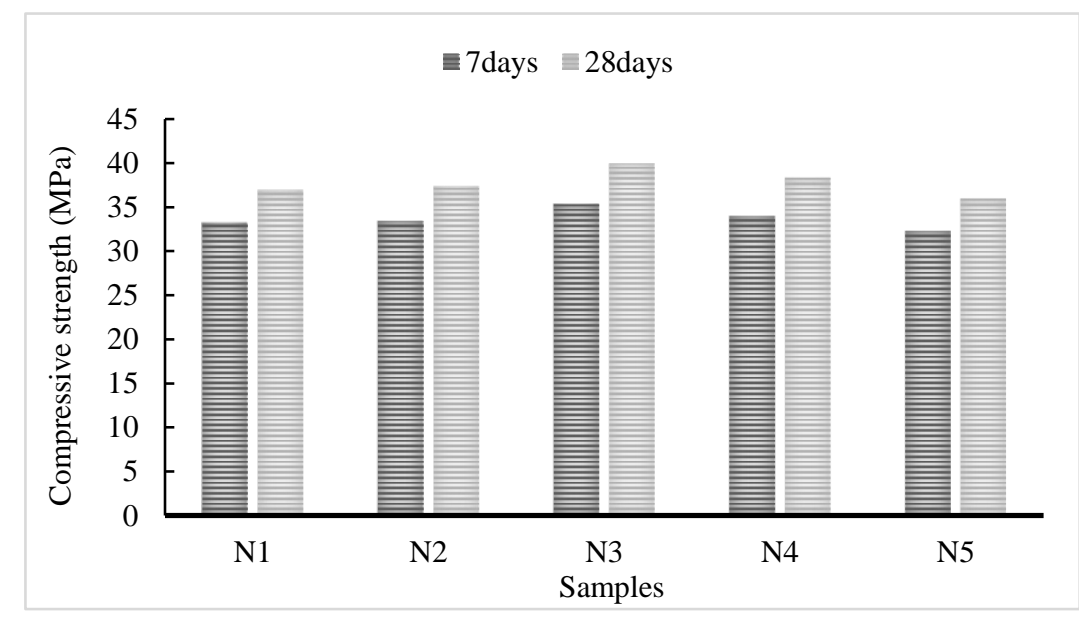

Figure 5. Compressive strength results (7 and 28 Days)

\subsection{Flexural Strength}

Flexural strength of samples aged 28 days was tested for three samples per design and the average results are presented in Table 7. As can be seen in Figure 6, increasing the fiber content, the flexural strength of lightweight concrete examples has been increased.

The flexural strength of N4 increase about 6 percent compared with N1. Because by using Polyolefin fiber the bond improved and to be caused by decrease of air voids at the fiber-matrix interface. The N5 sample having better performance than N1. It is observed that the increase in flexural strength is 1.3 percent for N5 samples.

Table 7. Test results for flexural strength

\begin{tabular}{cc}
\hline Sample & Average Flexural strength for 28 days (MPa) \\
\hline $\mathrm{N}_{1}$ & 1.894 \\
$\mathrm{~N}_{2}$ & 1.9 \\
$\mathrm{~N}_{3}$ & 1.977 \\
$\mathrm{~N}_{4}$ & 2.01 \\
$\mathrm{~N}_{5}$ & 1.92 \\
\hline
\end{tabular}




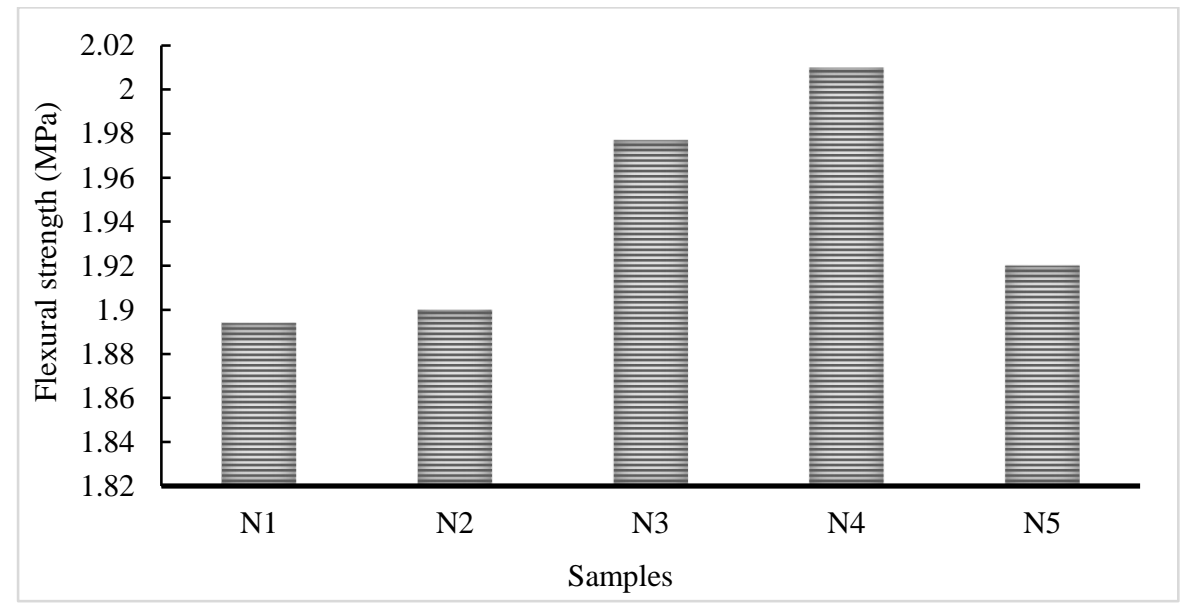

Figure 6. Flexural strength results (28 Days)

\subsection{Splitting Tensile Strength}

Splitting Tensile Strength of samples aged 28 days was tested for three samples per design and the average results are presented in Table 8. Results of splitting tensile strength of lightweight concrete samples are shown in Figure 7. As can be seen, the increase of fibers to lightweight concrete increases the tensile strength of concrete. N5 sample has shown the lowest tensile strength compared with other samples and about $16 \%$ compared with N1.

Although, by adding fibers, the samples of N2, N3 and N4 has shown increase in splitting tensile strength of light weight concrete with slight different. The length, dosage and shape of fiber effects on splitting tensile strength. Polyolefin fiber with scalloped shape, provides the best bond to the cementitious matrix and increasing the splitting tensile strength.

Table 8. Test results for Splitting Tensile Strength

\begin{tabular}{cc}
\hline Sample & Average Flexural strength for 28 days (MPa) \\
\hline $\mathrm{N}_{1}$ & 3.61 \\
$\mathrm{~N}_{2}$ & 3.9 \\
$\mathrm{~N}_{3}$ & 3.96 \\
$\mathrm{~N}_{4}$ & 3.98 \\
$\mathrm{~N}_{5}$ & 3.02 \\
\hline
\end{tabular}

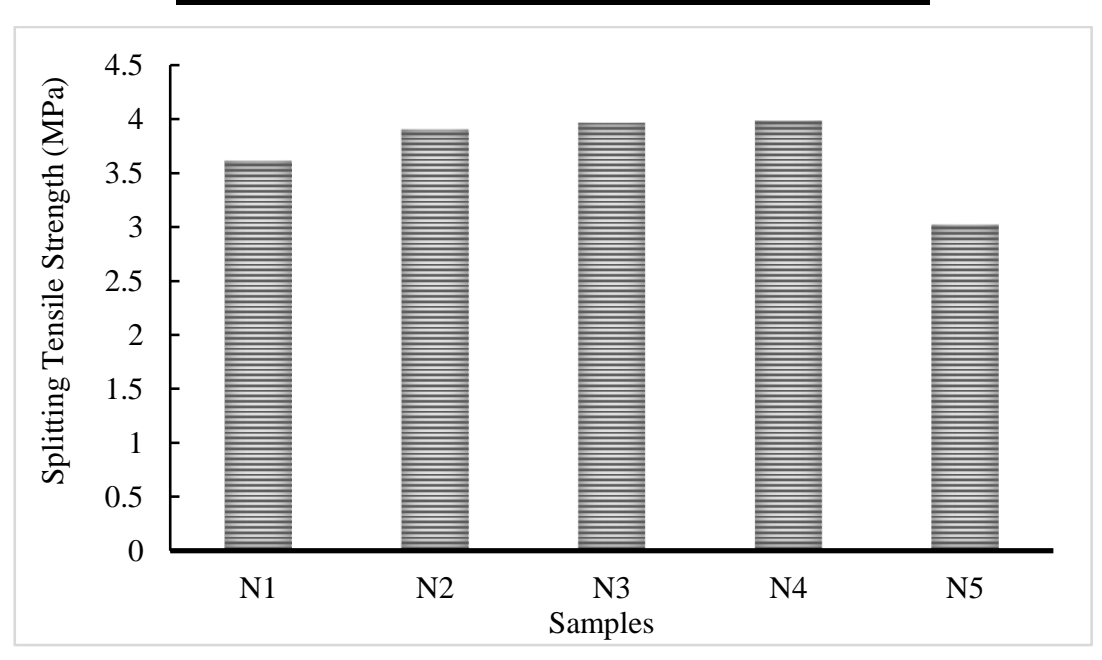

Figure 7. Splitting Tensile Strength results (28 Days)

\section{Conclusion}

Overall, the results revealed that the presence of Polyolefin fibers produced in industrial units could create relatively more powerful lightweight concrete in terms of the mechanical properties. Addition of Polyolefin fiber in lightweight LECA concrete increased compressive strength by $8 \%$ after 28 days of storage at N3. Enhances the strength properties of the concrete and in most cases it improves the efficiency of the fibers in the matrix structure of concrete. Addition of 1 and $1.5 \%$ fibers increased the flexural strength by $4.4 \%$ and $6 \%$, respectively. Fiber was effective on the tensile strength as such $0.5,1$, and $1.5 \%$ fibers significantly increased the Brazilian tensile strength of the samples about $10 \%$. 


\section{References}

[1] Colangelo, S, Cioffi, R, Liguori, B, Iucolano, F. "Recycled polyolefins waste as aggregates for lightweight concrete", Composites Part B 106, (2016), 234-241.

[2] Chandra, S, Berntsson, L,'Light weight aggregate concrete”, Elsevier, 2002.

[3] Brandt A. "Fiber reinforced cement-based (FRC) composites after over 40 years of development in building and civil engineering", Compos Structure 2008; 86(1-3):3-9.

[4] Ivorra S, Garces P, Catala G, Andion LG, Zornoza E. "Effect of silica fume particle size on mechanical properties of short carbon fiber reinforced concrete", Mater Des 2010; 31(3):1553-8.

[5] Han, T-Y, Lin, W-T, Cheng, A, Huang, R, Huang, C-C. "Influence of polyolefin fibers on the engineering properties of cementbased composites containing silica fume”, Mater Des 2012; 37: 569-76.

[6] Vandewalle, L, "Postcracking behaviour of hybrid steel fiber reinforced concrete", In Fracture Mechanics of Concrete and Concrete Structures- FraMCoS, in: Proceedings of the 6th International Conference, Catania, Italy, 2007, pp. 17-22.

[7] Yao, W, Li, J, Wu, K," Mechanical properties of hybrid fiber-reinforced concrete at low fiber volume fraction”, Cem. Concr. Res. 33 (1) (2003) 27-30.

[8] Pakravan, H.R, Latifi, M, Jamshidi, M,“Hybrid short fiber reinforcement system in concrete: A review”, Construction and Building Materials 142 (2017) 280-294.

[9] Alberti, MG, Enfedaque, A, Galvez, JC. "On the mechanical properties and fracture behavior of polyolefin fiber-reinforced selfcompacting concrete", Constr Build Mater 2014; 55(31):274-88.

[10] Behfarnia, K, Behravan, A. “Application of high performance polypropylene fibers in concrete lining of water tunnels”, Mater Des 2014; 55: 274-9.

[11] Wolfgang, H, Naaman, A,’High performance fiber reinforced cement composites”, 3rd International RILEM Workshop.

[12] Tagnit, A, Vanhove, Y, Petrov, N," Microstructural analysis of the bond mechanism between polyolefin fibers and cement pastes", Cement and concrete research, Vol 35, pp 364-370, 2005.

[13] Ramakrishnan, V., "Performance characteristics of polyolefin fiber reinforced concrete", Proceedings of the Materials Engineering Conference: Materials for the New Millennium, 1: pp. 93-102, 1996. 